\title{
PEMBERDAYAAN MASYARAKAT NON PRODUKTIF MELALUI KETERAMPILAN PEMBUATAN BALSEM STICK JAHE DI PESANTREN YAPISA LEUWILIANG BOGOR
}

\author{
Muhammad Fathurrahman ${ }^{1}$, Usep Suhendar ${ }^{1}$ \\ ${ }^{1}$ Fakultas Matematika dan Ilmu Pengetahuan Alam, Universitas Pakuan \\ Email: fathur110590@unpak.ac.id
}

\begin{abstract}
Abstrak
Mitra yang terlibat dalam kegiatan Pengabdian pada Masyarakat ini adalah Pondok Pesantren YAPISA. Pondok Pesantren YAPISA merupakan suatu lembaga non-profit yang bergerak di bidang pendidikan. Lembaga ini masih memiliki permasalahan dalam hal bidang teknologi dan ekonomi. Masyarakat kelompok ini kami jadikan sebagai mitra untuk diberikan keterampilan membuat balsem stick jahe dengan harapan keterampilan ini mampu mengangkat masyarakat untuk berkarya dan menjadi masyarakat yang produktif sehingga dapat meningkatkan kesejahteraan ekonomi. Mitra yang melakukan program ini adalah para santri dan guru di lingkungan Pondok Pesantren YAPISA. Pelaksanaan program ini dilakukan melalui pelatihan keterampilan pembuatan balsem jahe stick untuk skala industri rumah tangga secara detail, kontinyu dan tuntas sampai dihasilkan produk balsem dengan kualitas yang baik. Selain itu, dilakukan pelatihan pengemasan dan pelabelan produk balsem dalam kemasan. Pelatihan dilanjutkan dengan pembinaan serta pendampingan mitra dalam memulai membuat toko online. Hasil program pemberdayaan masyarakat non produktif melalui keterampilan membuat balsem stick jahe ini adalah model pemberdayaan masyarakat, mencakup terbukanya wawasan masyarakat non-produktif mengenai peluang usaha pembuatan balsem, menghasilkan tenaga-tenaga terampil, menghasilkan produk balsem yang berkualitas baik dan siap untuk dipasarkan dan membuka peluang untuk direkomendasikan menjadi usaha kecil mandiri yang lebih potensial sehingga dapat meningkatkan pendapatan masyarakat yang berimbas pada peningkatan kesejahteraan.
\end{abstract}

Kata kunci: Balsem Stick Jahe, Pondok Pesantren YAPISA, Program Kemitraan Masyarakat Stimulus

\section{PENDAHULUAN}

Yayasan Pendidikan Islam Saefulloh Assa'diyyah (YAPISA) adalah suatu lembaga pendidikan yang berada di wilayah Desa Leuwiliang Kecamatan Leu- wiliang Kabupaten Bogor. YAPISA merupakan lembaga pendidikan yang sedang berkembang, karena lembaga ini baru didirikan pada tahun 2012. Sampai tahun ini, lembaga tersebut baru menyelenggarakan tiga satuan pendidikan, yai- 
DIFUSI

Volume 3, No.2 Juli 2020

tu PAUD, SD, dan SMP. Selain itu juga terdapat Pondok Pesantrennya. Lembaga ini sangat memperhatikan anak yatim. Seluruh biaya pendidikan untuk anak yatim dibebaskan. Berdasarkan hasil observasi pada tanggal 7 Oktober 2018, kami mendapatkan informasi bahwa lembaga ini masih kekurangan dalam sisi keuangan, sehingga lembaga tersebut kesulitan dalam pengembangan sarana dan prasarananya. Hal ini disebabkan karena jumlah murid yang terdaftar di sekolah tersebut masih sangat sedikit, serta SPP yang dibebankan kepada peserta didik masih sangat rendah. Lembaga ini kami jadikan sebagai mitra karena memiliki siswa dan guru yang sangat bersemangat dan memiliki kemampuan yang baik untuk dapat ikut serta dalam pembuatan produk balsem stick jahe.

Pondok Pesantren YAPISA terletak di Desa Leuwiliang yang secara geografis berada di pusat Kecamatan Leuwiliang, sebelah barat ibu kota Kabupaten Bogor dengan jarak 36,6 km dan waktu tempuh sekitar 1 jam 14 menit. Posisinya yang cukup jauh dari ibu kota Kabupaten Bogor menyebabkan peningkatan sarana prasarana serta perekonomian masyarakat Desa Leuwiliang bergerak sangat lambat.

Dua tahun yang lalu ada Program Pengabdian Pada Masyarakat di Pondok Pesantren tersebut, yaitu pemberdayaan masyarakat non produktif melalui pembuatan tawas dari limbah kaleng bekas minuman. Kegiatan tersebut tidak berlanjut karena dalam proses pengolahannya dibutuhkan bahan-bahan yang berbahaya seperti asam sulfat. Masyarakat mengkhawatirkan penggunaan bahan ki- mia yang berbahaya sehingga dapat membahayakan masyarakat [1].

Program ini dapat memberikan nilai tambah jika ditinjau dari dua sisi yang berbeda. Pertama, melalui pembuatan balsem stick jahe ini dapat meningkatkan nilai jual dari jahe. Kedua, dapat mengatasi masalah penduduk yang belum memiliki pekerjaan sehingga menjadi pengusaha industri balsem stick jahe. Pada program ini digunakan jahe sebagai bahan baku karena banyak mengandung gingerol, shogaol dan Zingerone yang memberi efek farmakologi dan fisiologi seperti antioksidan, antiinflamasi, analgesik, antikarsinogenik, non-toksik dan non-mutagenik meskipun pada konsentrasi tinggi [2].

Berdasarkan analisis situasi maka, permasalahan yang dialami mitra dapat dirumuskan sebagai berikut:

a. Mitra mengalami kesulitan dalam bidang ekonomi, seperti gaji guru masih rendah dan terhambatnya pembangunan sarana dan prasarana.

b. Masih terbatasnya modal kerja mitra untuk mengembangkan produksi barang dalam skala besar.

c. Perlu keterampilan khusus untuk membuat dan mengembangkan produk baru.

Berdasarkan hal tersebut disepakati (tim pengusul dan mitra) dan disimpulkan bahwa penentuan masalah prioritas dilakukan dengan melihat dan mengkaji masalah yang hingga saat ini belum dilakukan upaya yang signifikan untuk mengatasinya. Oleh karena itu dari berbagai masalah yang ada, dipilihlah prioritas masalah yaitu perlu keterampilan 
khusus untuk membuat dan mengembangkan produk balsem stick jahe.

\section{METODE}

Berdasarkan masalah prioritas yang telah disepakati bersama, maka terdapat 3 (tiga) pendekatan yang ditawarkan sebagai solusi.

\section{Memberikan Pelatihan Keteram-} pilan Pembuatan Balsem Stick Jahe untuk Skala Industri Rumah Tangga Secara Detail, Kontinyu dan Tuntas sampai Dihasilkan Produk dengan Kualitas yang Baik

a. Pelatihan dimulai dengan pemberian materi untuk menambah wawasan mitra mengenai balsem stick jahe dan manfaatnya dalam kehidupan sehari-hari dan di industri. Dalam pelatihan ini juga diberikan wawasan tentang cara pembuatan balsem stick jahe. Tahap awal ini akan dilakukan selama kurang lebih satu bulan pertama.

b. Tahap kedua dilakukan pada bulan kedua yaitu pelatihan membuat balsem stick jahe.

c. Tahap ketiga akan dilakukan evaluasi apakah para mitra sudah memahami cara pembuatan balsem stick jahe dan sudah bisa menghasilkan balsem yang baik. Apabila mitra belum bisa menghasilkan kualitas balsem yang baik, maka akan diulangi tahap kedua.

d. Tahap keempat akan dilakukan uji coba balsem stick jahe untuk menghangatkan badan. Tahap keempat ini dilakukan pada bulan keempat.

\section{Memberikan Pelatihan Penge- masan dan Pelabelan Balsem}

Pengemasan merupakan sistem yang terkoordinasi untuk menyiapkan barang menjadi barang yang siap untuk didistribusikan, disimpan, dijual atau dipakai, sedangkan pelabelan dimaksudkan untuk memberi keterangan isi dari kemasan barang/produk dan nama produsennya. Penggunaan logo juga sangat penting. Logo merupakan identitas produk yang sesuai dengan produk, khas, berbeda dengan logo lainnya, dan mudah diingat oleh pembeli [3].

\section{Memberikan Pelatihan Internet Marketing dan Pembuatan Toko Online}

Toko atau pasar merupakan tempat pelepasan produk yang didalamnya terdapat persaingan harga, dimana pembeli akan memilih produk yang berkualitas dengan harga yang murah. Harga yang kompetitif merupakan prioritas yang harus diperhatikan agar masyarakat memiliki daya beli yang tinggi.

Saat ini sistem jual beli sudah mulai beralih ke dunia digital. Pembeli dan penjual tidak perlu lagi tatap muka secara langsung. Hal ini menyebabkan proses jual beli menjadi lebih praktis. Pengetahuan ini perlu disampaikan kepada mitra agar mereka dapat membuat toko online sendiri di media-media e-commerce yang sudah tersedia di Negara Indonesia.

Promosi produk secara online dapat dilakukan menggunakan berbagai media 
DIFUSI

Volume 3, No.2 Juli 2020

sosial. Banyak contoh kegiatan pengabdian kepada masyarakat yang menggunakan metoda ini. Setiawan [4] melakukan pemanfaatan internet marketing untuk mempersiapkan masyarakat kreatif dan berjiwa wirausaha mandiri di lingkungan warga PKK. Putri [5] melakukan kegiatan pelatihan pemasaran online produk olahan unik ampas tahu sebagai bentuk diversifikasi produk menggunakan hasil proses pengolahan limbah sederhana industri tahu. Sosianika [6] melakukan kegiatan penguatan kinerja pemasaran melalui promosi online produk kelompok UMKM Tongtengpakcur Tasikmalaya, Jawa Barat.

\section{HASIL DAN PEMBAHASAN}

Kegiatan Program Kemitraan Masyarakat Stimulus (PKMS) dengan judul "Pemberdayaan Masyarakat Non Produktif Melalui Keterampilan Pembuatan Balsem Stick Jahe di Lingkungan Pondok Pesantren YAPISA Leuwiliang Bogor" yang diketuai oleh Muhammad Fathurrahman, S.Pd, M.Si, dengan Anggota Usep Suhendar, S.Pd, M.Si, dari Universitas Pakuan telah dilaksanakan mulai dari Sosialisasi Program sampai kepada pelatihan pembuatan toko online. Kerja sama yang baik terjadi antara tim pelaksana dengan mitra sehingga kegiatan demi kegiatan dapat berjalan baik dengan tahapan sebagai berikut.

\section{Sosialisasi Program Kemitraan Masyarakat Stimulus (PKMS)}

Sosialisasi Program Kemitraan Masyarakat Stimulus (PKMS) telah dilakukan pada tanggal 15 Juni 2019 sebagai upaya untuk menyampaikan informasi ada- nya program kegiatan ini serta manfaatnya bagi masyarakat, sekaligus kami meminta komitmen mereka untuk mengikuti kegiatan ini secara tuntas pada setiap tahap kegiatannya. Foto kegiatan pada saat sosialisasi kegiatan oleh Tim Pengabdian Pada Masayarakat yang dihadiri oleh masyarakat non produktif dapat dilihat pada Gambar 1 dan 2.

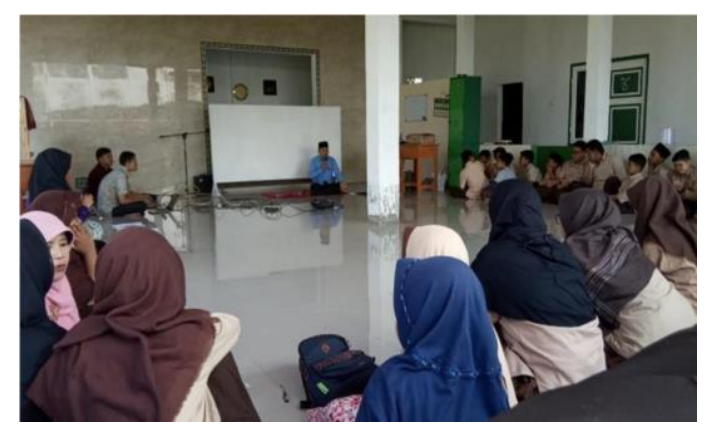

Gambar 1. Sambutan dari mitra Pengasuh Pondok Pesantren YAPISA

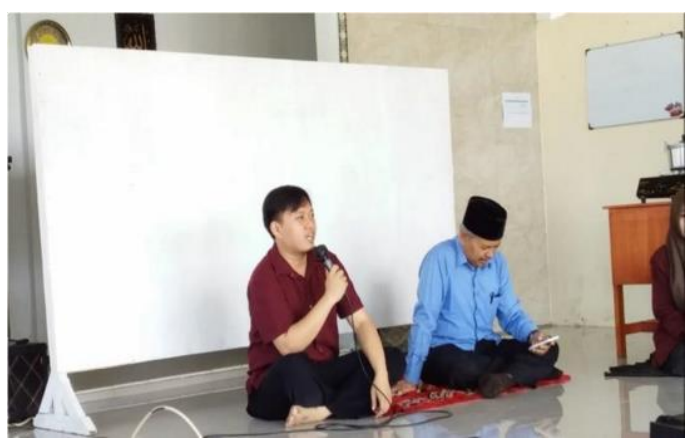

Gambar 2. Sambutan dari Ketua Tim Abdimas sekaligus Sosialisasi Program

Kegiatan Sosialisasi Program ini dihadiri oleh 32 peserta yang terdiri atas siswa, guru, dan pengurus Pondok Pesantren YAPISA yang siap mengikuti kegiatan ini pada tahap-tahap selanjutnya. Mereka sangat menantikan kegiatan seperti ini, yang sangat bermanfaat bagi mereka untuk menambah ilmu pengetahuan bahkan keterampilan yang dapat mereka manfaatkan untuk meningkatkan kesejahteraan mereka. 
DIFUSI

Volume 3, No.2 Juli 2020

\section{Penyuluhan Tata Cara Pembuat- an Balsem Stick Jahe}

Kegiatan penyuluhan tata cara pembuatan balsem stick jahe dilakukan pada tanggal 29 Juni 2019. Penyuluhan ini diberikan agar mitra dapat mengetahui dengan jelas bagaimana proses pembuatan balsem stick jahe, alat dan bahan apa saja yang digunakan, serta bagaimana cara menggunakan alat dan bahan tersebut.

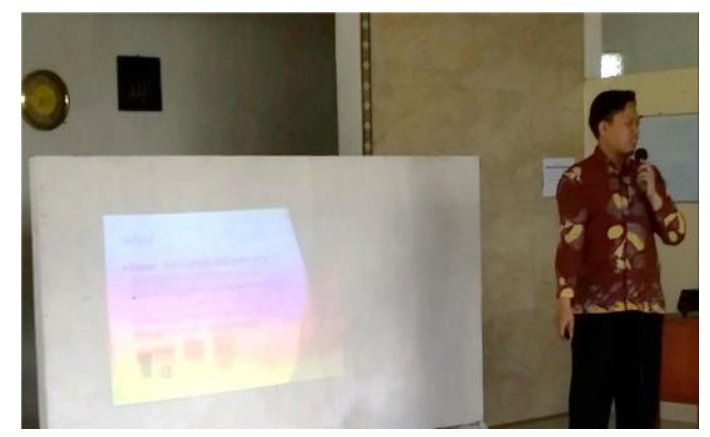

Gambar 3 Tim Abdimas sedang memberikan penyuluhan tata cara pembuatan balsem

Pada pelaksanaannya, penyuluhan tata cara pembuatan balsem stick jahe ini dihadiri oleh 32 orang. Jumlah ini sama pada saat sosialisasi program. Hal ini menunjukkan bahwa mitra memang sudah berkomitmen untuk dapat mengikuti setiap tahapan program sampai selesai.

Berdasarkan pengamatan kami, terlihat mereka antusias memperhatikan penjelasan bagaimana cara membuat balsem stick jahe. Hal ini disebabkan karena hal ini merupakan hal yang baru dan sangat bermanfaat bagi mereka.

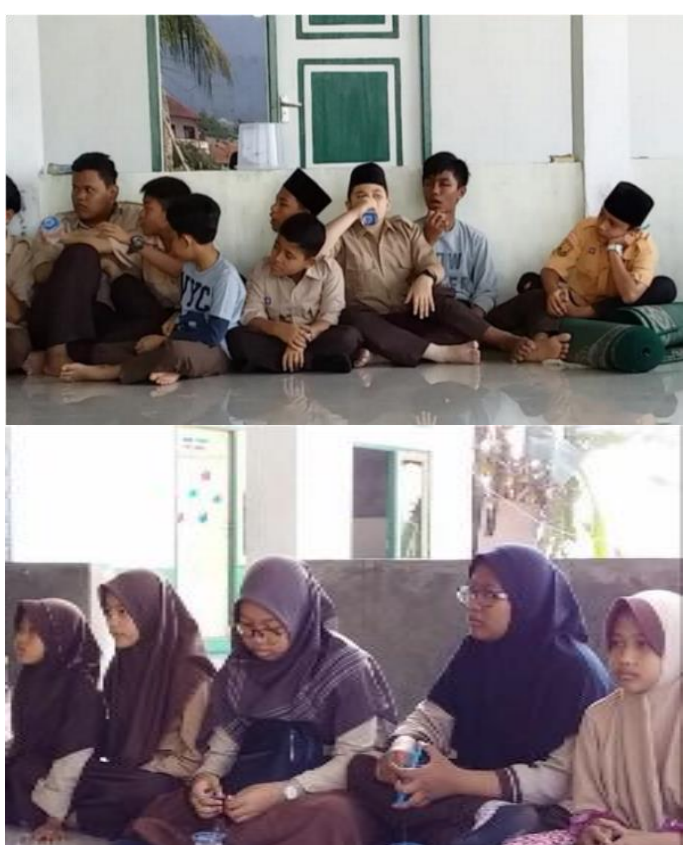

Gambar 4. Mitra sedang menyimak penjelasan saat penyuluhan

\section{Sosialisasi Program Kemitraan Masyarakat Stimulus (PKMS)}

Kegiatan Demonstrasi dan Praktek pembuatan balsem stick jahe dilakukan pada tanggal 13 Juli 2019 ini dihadiri oleh 32 orang. Peserta yang hadir pada pelatihan ini sama dengan yang hadir pada saat penyuluhan. Hal ini menunjukkan bahwa masyarakat sangat antusias ingin segera mempraktekkan pengetahuan yang sudah didapatnya pada saat penyuluhan. Gambar 5, 6, dan 7 adalah foto-foto dokumentasi pada saat pelatihan pembuatan balsem stick jahe.

Mitra terlihat merasa sangat senang karena berhasil membuat sesuatu yang belum pernah mereka lakukan sebelumnya yaitu membuat balsem stick jahe. Beberapa bahan baku pembuatan balsem pun baru pertama kali mereka dengar. Adapun komposisi bahan baku yang 
DIFUSI

Volume 3, No.2 Juli 2020

digunakan pada saat percobaan adalah 50 gram vaselin, 5 gram paraffin, minyak gandapura $5 \mathrm{~mL}$, eugenol (minyak cengkeh) $1 \mathrm{~mL}$, menthol kristal 5 gram, dan 2 sendok makan bubuk jahe putih. Semua bahan-bahan tersebut dimasukkan ke dalam panci dan panaskan menggunakan api kecil. Adonan yang telah dibuat di panci kemudian dimasukkan ke dalam wadah balsem yang berupa stick.

Pada kegiatan tersebut dihasilkan sekitar 15 buah balsem stick jahe yang siap digunakan. Berikut foto dokumentasi Tim Abdimas bersama mitra sambil memperlihatkan produk balsem stick jahe yang telah dibuat.

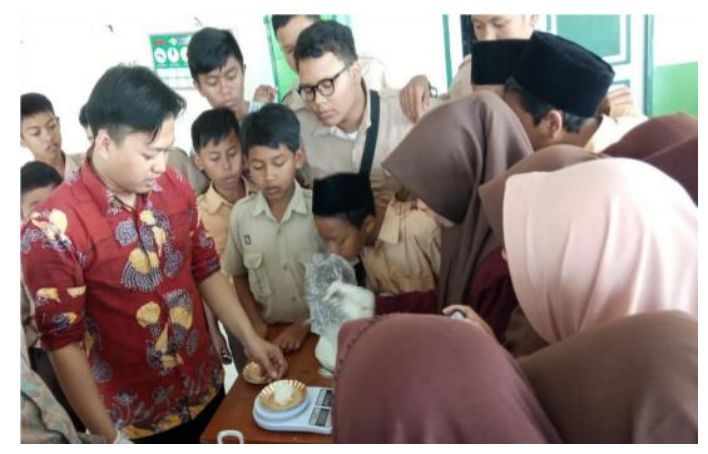

Gambar 5 Mitra mencoba menimbang vaselin

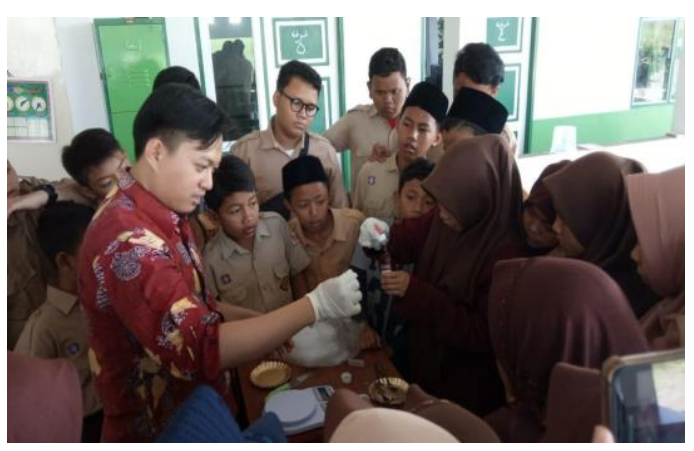

Gambar 6. Mitra sedang mencoba memipet minyak gandapura

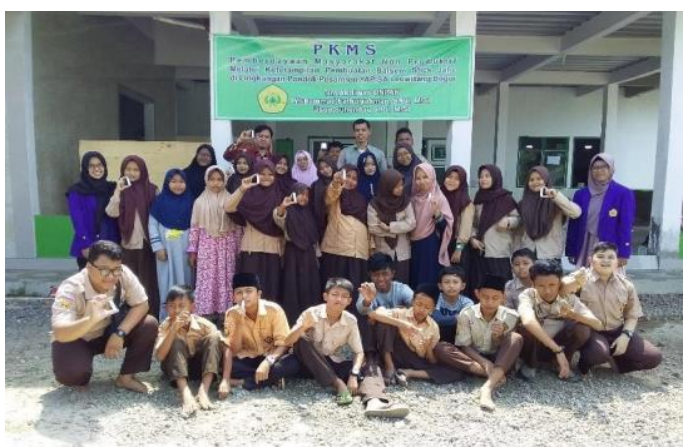

Gambar 7 Foto Tim Abdimas bersama Mitra setalah Praktek Pembuatan Balsem Stick Jahe

\section{Sosialisasi Program Kemitraan Masyarakat Stimulus (PKMS)}

Kegiatan penyuluhan pelabelan produk balsem stick jahe dilakukan pada tanggal 27 Juli 2019. Kegiatan ini dilakukan agar mitra mendapatkan bekal pengetahuan tentang jenis-jenis label yang harus ada dalam suatu produk. Berikut adalah foto dokumentasi pada kegiatan penyuluhan pelabelan produk balsem stick jahe.
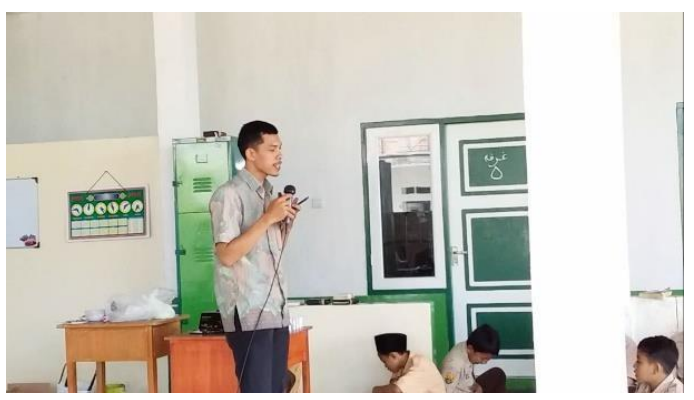

Gambar 8. Suasana penyuluhan pelabelan produk balsem stick jahe

\section{Praktek Pelabelan Produk Bal- sem Stick Jahe}

Kegiatan praktek pelabelan produk balsem stick jahe ini dilaksanakan pada 
DIFUSI

Volume 3, No.2 Juli 2020

tanggal 30 November 2019. Pada kegiatan ini, mitra dibagi menjadi beberapa kelompok untuk mendiskusikan tentang label produk balsem stick jahe. Pada kegiatan ini juga disepakati nama produk untuk balsem stick jahe yang telah dibuat yaitu Bazetik yang merupakan kepanjangan dari Balsem Jahe Stick. Gambar 9 adalah foto dokumentasi pada kegiatan praktek pelabelan produk balsem stick jahe.

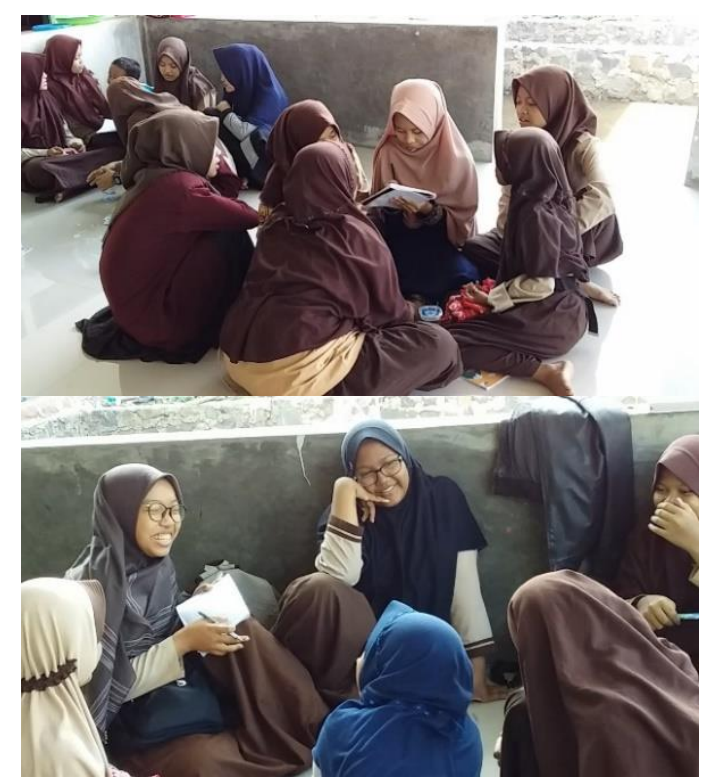

Gambar 9 Mitra sedang mendiskusikan label produk balsem stick jahe

\section{Penyuluhan Pemasaran Produk Balsem Stick Jahe}

Kegiatan Praktek Pemasaran Produk Balsem Stick Jahe ini dilaksanakan pada tanggal 07 Desember 2019. Pada kegiatan ini mitra diberikan pengetahuan bagaimana memasarkan produk di dalam jaringan (online). Hasil dari kegiatan ini adalah mitra akhirnya telah memiliki Toko dalam jaringan di aplikasi Tokopedia yang diberi nama YAPISA MART. Meskipun produk balsem stick jahe belum bisa dipasarkan karena belum memiliki izin dari BPOM namun mitra sudah memiliki produk lain berupa buku yang dapat dipasarkan di toko tersebut. Gambar 10 dan 11 adalah dokumentasi dari kegiatan penyuluhan pemasaran produk balsem stick jahe.

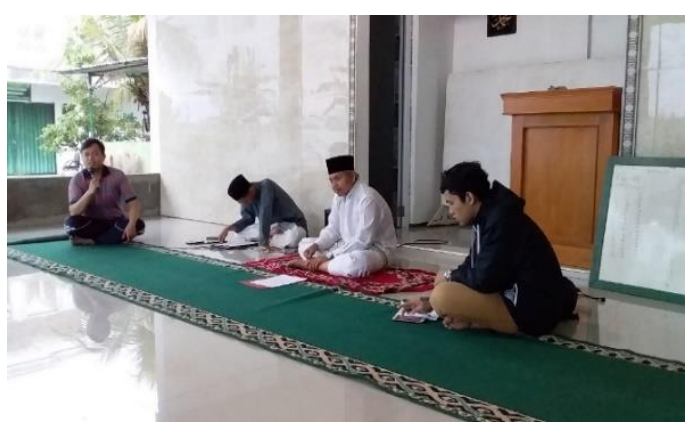

Gambar 10. Mitra sedang diberikan penyuluhan tentang pemasaran dalam jaringan

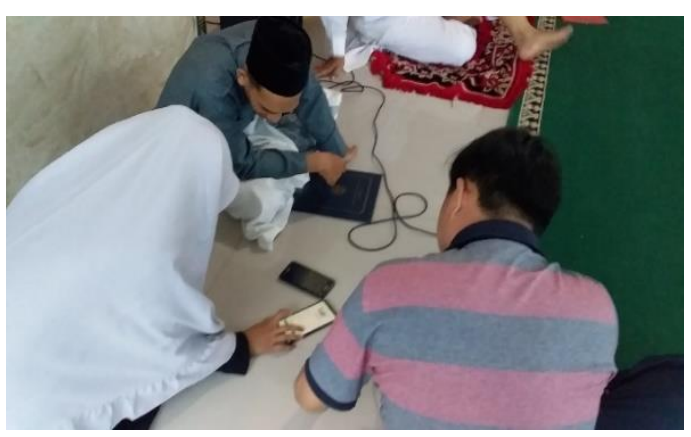

Gambar 11. Mitra sedang dibimbing dalam membuat toko dalam jaringan

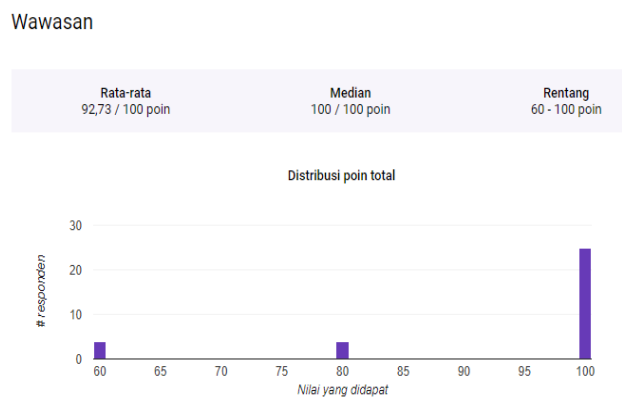

Gambar 12. Profil wawasan mitra setelah Program PKMS dilaksanakan 
DIFUSI

Volume 3, No.2 Juli 2020

Demikian kegiatan Program Kemitraan Masyarakat Stimulus (PKMS) yang telah kami lakukan. Mitra mengalami banyak kemajuan dari segi wawasan dan keterampilannya. Hal ini dapat terlihat dari hasil postest yang dilakukan setelah kegiatan dilaksanakan. Grafik penguasaan wawasan mitra setelah dilakukan pendampingan ditampilkan pada Gambar 12.

\section{KESIMPULAN}

Berdasarkan Program Kemitraan Masyarakat Stimulus (PKMS) yang telah dilakukan, dapat disimpulkan bahwa:

a. Mitra terbuka wawasannya mengenai peluang usaha dari produk balsem stick jahe.

b. Mitra memiliki keterampilan membuat balsem stick jahe.

c. Mitra memiliki toko dalam jaringan yang bernama YAPISA MART.

Saran untuk pelaksanaan program kemitraan masyarakat selanjutnya adalah:

a. Promosi produk balsem stick jahe diperluas menggunakan berbagai media sosial.

b. Mendapatkan izin dari BPOM agar produk balsem stick jahe bisa diedarkan dan dipasarkan

\section{UCAPAN TERIMAKASIH}

Ucapan terima kasih disampaikan kepada Direktorat Riset dan Pengabdian Masyarakat, Direktorat Jenderal Penguatan Riset dan Pengembangan, Kementerian Riset, Teknologi, dan Pendidikan Tinggi, yang telah mendukung secara finan- sial untuk Program Kemitraan Masyarakat Stimulus ini sesuai dengan Surat Kontrak Nomor : 108/SP2H/PPM/ DR$\mathrm{PM} / 2019$, tanggal 8 Maret 2019.

\section{REFERENSI}

[1] A. Ryani, S. Sutanto, dan M. Fathurrachman, "Pemberdayaan Masyarakat Non Produktif Melalui Keterampilan Pembuatan Tawas Dari Limbah Kaleng Bekas Minuman," Qardhul Hasan: Media Pengabdian Kepada Masyarakat, 3(2), pp. 99. doi: 10.30997/qh.v3i2.945. 2017.

[2] S. Suparmi, "Peningkatan Pengetahuan Remaja Tentang Manfaat Jahe Merah Terhadap Penurunan," GEMASSIKA: Jurnal Pengabdian kepada Masyarakat, 1(1), pp. 47, doi: 10.30787/gemassika.v1i1.218, 2017.

[3] A. P. Wardanu, U. Martanto, "Perbaikan desain kemasan stik ale-ale dan stik kangkung produksi kub wida mantolo di kecamatan benua kayong kabupaten ketapang," DIFUSI, 1(2), pp. 11-21. 2018.

[4] Irwan Setiawan, "Pemanfaatan Internet Marketing untuk Mempersiapkan Masyarakat Kreatif dan Berjiwa Wirausaha Mandiri di Lingkungan Warga PKK," DIFUSI, 2(2), pp. 45-53, 2019.

[5] I. S. S. Putri, D. Rahmawati dan N. N. Sari, "Pemasaran Online Produk Olahan Unik Ampas Tahu Sebagai Bentuk Diversifikasi Produk Menggunakan Hasil Proses Pengolahan Limbah Se- 
DIFUSI

Volume 3, No.2 Juli 2020

derhana Industri Tahu," DIFUSI, 2(1), pp. 41-48. 2019.

[6] A. Sosianika, L. Kusdibyo, "Penguatan Kinerja Pemasaran melalui Promosi Online Produk Kelompok Umkm Tongtengpakcur Tasikmalaya, Jawa Barat', DIFUSI, 1(2), pp. 22-30, 2018. 